Article

\title{
Serum $\gamma$-Glutamyltransferase Concentration Predicts Endothelial Dysfunction in Naïve Hypertensive Patients
}

\author{
Maria Perticone ${ }^{1, *,+}$, Raffaele Maio ${ }^{2,+} \mathbb{C}$, Benedetto Caroleo ${ }^{2}$, Angela Sciacqua ${ }^{3}$, \\ Edoardo Suraci ${ }^{3}$, Simona Gigliotti ${ }^{3}$, Francesco Martino ${ }^{4}$, Francesco Andreozzi ${ }^{3}$ (D), \\ Giorgio Sesti ${ }^{5}$ (D) and Francesco Perticone ${ }^{3}$ (D) \\ 1 Department of Experimental and Clinical Medicine, Magna Graecia University, 88100 Catanzaro, Italy \\ 2 Geriatrics Division, University Hospital Mater Domini, 88100 Catanzaro, Italy; raf_maio@yahoo.it (R.M.); \\ benedettocaroleo@libero.it (B.C.) \\ 3 Department of Medical and Surgical Sciences, Magna Graecia University, 88100 Catanzaro, Italy; \\ sciacqua@unicz.it (A.S.); edoardosuraci88@gmail.com (E.S.); simona_gigliotti@yahoo.it (S.G.); \\ andreozzif@unicz.it (F.A.); perticone@unicz.it (F.P.) \\ 4 Department of Pediatrics Gynecology and Obstetrics, Sapienza University of Rome, 00185 Rome, Italy; \\ francesco.martino30@tin.it \\ 5 Department of Clinical and Molecular Medicine, Sant' Andrea University Hospital, \\ Sapienza University of Rome, 00185 Rome, Italy; giorgio.sesti@uniroma1.it \\ * Correspondence: mariaperticone@unicz.it; Tel.: +39-0961-364-7149 \\ + These Authors contributed equally to this work.
}

Received: 4 June 2020; Accepted: 9 July 2020; Published: 11 July 2020

\begin{abstract}
Background: Serum gamma-glutamyltransferase $(\gamma-\mathrm{GT})$ is recognized as a risk factor for cardiovascular diseases $(\mathrm{CV})$. Traditional cardiovascular risk factors mediate endothelial dysfunction. Aim: to evaluate a possible correlation between serum $\gamma$-GT and endothelium-dependent vasodilation in naïve hypertensives. Methods: We enrolled 500 hypertensives. Endothelial function was studied by strain-gauge plethysmography. Receiver operating characteristic (ROC) analysis was used to assess the predictive value of $\gamma$-GT and to identify the optimal cut-off value of the same variable for endothelial dysfunction. Results: At univariate linear analysis peak percent increase in acetylcholine (ACh)-stimulated vasodilation was inversely related to $\gamma$-GT $(r=-0.587)$, alanine aminotransferase (ALT) $(r=-0.559)$, aspartate aminotransferase (AST) $(r=-0.464)$, age $(r=-0.171)$, body mass index (BMI) $(r=-0.152)$, and fasting glucose $(r=-101)$. In the stepwise multivariate regression model, endothelium-dependent vasodilation was significantly related to $\gamma$-GT $(\beta=-0.362)$, ALT ( $\beta=-0.297)$, AST $(\beta=-0.217)$, estimated glomerular filtration rate (e-GFR) $(\beta=0.199)$, gender $(\beta=0.166)$, and smoking $(\beta=-0.061)$. The ROC analysis demonstrated that the accuracy of $\gamma$-GT for identifying patients with endothelial dysfunction was $82.1 \%$; the optimal $\gamma$-GT cut-off value for discriminating patients with this alteration was $27 \mathrm{UI} / \mathrm{L}$. Conclusions: Serum $\gamma$-GT values, within the normal range, are significantly associated with endothelial dysfunction in hypertensives, and may be considered a biomarker of early vascular damage.
\end{abstract}

Keywords: serum $\gamma$-glutamyltransferase; endothelial dysfunction; essential hypertension; atherosclerosis; cardiovascular risk factors

\section{Introduction}

Gamma-glutamyltransferase $(\gamma-\mathrm{GT})$ is a glycoprotein located on the plasma membranes of most cells and organ tissues, especially of hepatocytes. It is involved in the extracellular catabolism of 
glutathione, recognized as the major thiol antioxidant in humans and other mammals. An increase in serum $\gamma$-GT levels $>50 \mathrm{IU} / \mathrm{mL}$ is seen as a consequence of liver injury or bile ducts blockage. In clinical practice, serum $\gamma$-GT levels are routinely measured when hepatic/biliary disease and/or alcohol abuse are suspected [1], and it has recently been recognized as a risk factor for metabolic alterations [2], and chronic renal [3] and cardiovascular diseases (CV) [4-7]. These effects seem to be mediated by the capacity of $\gamma$-GT to increase the production of reactive oxygen species (ROS) in the presence of some transition metal such as iron $[4,8]$. Thus, on the basis of these findings and of other epidemiological studies, it was suggested to consider $\gamma$-GT, within its normal range, as an early and sensitive biomarker of oxidative stress [9]. In fact, subclinical inflammation related to oxidative stress is considered as the main pathogenetic mechanism involved in several cardio-metabolic diseases [10].

It is well established that endothelial dysfunction, an early event in the atherogenic process, is associated with some metabolic and hemodynamic [11-14] risk factors (i.e., arterial hypertension, obesity, etc.) sharing the same pathogenetic mechanisms, represented by an increased oxidative stress and subclinical inflammation. The activation of these pro-oxidant and pro-inflammatory pathways leads to the activation and progression of atherosclerotic disease by reducing nitric oxide (NO) bioavailability and its protective effect on vascular function $[15,16]$. In addition, it is important to remark that endothelial dysfunction has been demonstrated to predict the progression of subclinical target organ damage [17-19]; on this basis, it is possible to affirm that endothelial dysfunction has a key role in the pathogenetic mechanisms of CV diseases and associated outcomes [14]. Even if the association between essential hypertension and endothelial dysfunction is well established, to our knowledge there are no data testing a possible relationship between serum $\gamma$-GT concentrations and endothelial function in this setting of patients. Thus, we designed the present study to evaluate a possible association between serum $\gamma$-GT concentrations, within its normal range, and endothelium-dependent vasodilation, evaluated by strain-gauge plethysmography, in a large population of newly diagnosed, never-treated hypertensive patients.

\section{Experimental Section}

For this study we enrolled 500 Caucasian hypertensive outpatients (256 men and 244 women; mean age, $47 \pm 11$ years) referred to the Hypertension Clinic of the University Hospital of Catanzaro, Italy. Exclusion criteria were secondary forms of hypertension, clinical evidence or previous history of coronary artery disease, valvular heart disease, peripheral artery disease, diabetes mellitus, hypercholesterolemia, liver diseases, impaired renal function (defined as an estimated glomerular filtration rate [e-GFR] $<60 \mathrm{~mL} / \mathrm{min}$ per $1.73 \mathrm{~m}^{2}$ ), coagulopathies, vasculitis and/or Raynaud's phenomenon, history of alcohol and/or drug abuse, and the use of drugs interfering with liver enzyme concentrations. To enter the study protocol, all subjects had to have serum values of alanine aminotransferase (ALT), aspartate aminotransferase (AST), and $\gamma$-GT in the normal range; in particular, we considered $50 \mathrm{IU} / \mathrm{mL}$ as the upper normal limit for all these three variables, as established by our laboratory. At the first evaluation, all subjects underwent routine blood tests, assessment of risk factors for atherosclerosis, and evaluation of vascular function through strain-gauge plethysmography. ALT and AST were measured by pyridoxal phosphate activated (liquid reagent) (COBAS Integra 800-Roche Diagnostics GmbH, Mannheim, Germany; normal values 0-50 UI/L), $\gamma$-GT was evaluated by standardized against Szasz (COBAS Integra 800-Roche Diagnostics GmbH, Mannheim, Germany; normal values 8-50 UI/L).

High-sensitivity C-reactive protein (hs-CRP) was measured by a high-sensitivity turbidimetric immunoassay (Cardio-Phase hs-CRP, Siemens Healthcare Diagnostics GmbH, Marburg, Germany) in a subgroup of 400 patients representative of the whole study population with regard to the variables listed in Table 1.

The local ethics committee approved the study (approval number 2012.63, 23 October 2012-Comitato Etico Azienda Ospedaliero-Universitaria Mater Domini of Catanzaro, Italy), and all 
participants gave written informed consent for all procedures. All the study procedures were conducted according to the Declaration of Helsinki.

Table 1. Baseline characteristics of the whole study population and of the subgroup of patients with hs-CRP values.

\begin{tabular}{|c|c|c|c|}
\hline Variables & All $n=500$ & hs-CRP Group $n=400$ & $p$ \\
\hline Age, years & $47 \pm 11$ & $47 \pm 11$ & 0.998 \\
\hline Gender, M (\%) & $256(51)$ & $183(46)$ & 0.0001 \\
\hline Body mass index, $\mathrm{kg} / \mathrm{m}^{2}$ & $27.3 \pm 3.6$ & $27.3 \pm 3.6$ & 0.997 \\
\hline SBP, $\mathrm{mm} \mathrm{Hg}$ & $149 \pm 17$ & $149 \pm 17$ & 0.999 \\
\hline $\mathrm{DBP}, \mathrm{mm} \mathrm{Hg}$ & $91+12$ & $91 \pm 12$ & 0.998 \\
\hline Heart rate, bpm & $72 \pm 9$ & $73 \pm 9$ & 0.098 \\
\hline Total cholesterol, mg/dL & $205 \pm 31$ & $205 \pm 31$ & 0.997 \\
\hline Smokers, No (\%) & $78(16)$ & $75(19)$ & 0.246 \\
\hline Fasting glucose, $\mathrm{mg} / \mathrm{dL}$ & $95 \pm 11$ & $95 \pm 11$ & 0.998 \\
\hline LDL cholesterol, mg/dL & $130 \pm 31$ & $129 \pm 31$ & 0.631 \\
\hline HDL cholesterol, mg/dL & $52 \pm 12$ & $52 \pm 12$ & 0.997 \\
\hline Triglycerides, mg/dL & $116 \pm 40$ & $116 \pm 41$ & 0.999 \\
\hline $\mathrm{e}-\mathrm{GFR}, \mathrm{ml} / \mathrm{min} / 1.73 / \mathrm{m}^{2}$ & $85 \pm 20$ & $88 \pm 18$ & 0.020 \\
\hline ALT, UI/L & $21 \pm 11$ & $21 \pm 11$ & 0.999 \\
\hline AST, UI/L & $22 \pm 9$ & $22 \pm 9$ & 0.998 \\
\hline$\gamma-\mathrm{GT}, \mathrm{UI} / \mathrm{L}$ & $33 \pm 14$ & $32 \pm 14$ & 0.287 \\
\hline hs-CRP, mg/L & & $4.1 \pm 2.2$ & \\
\hline $\begin{array}{l}\text { FBF baseline, } \mathrm{mL} \cdot 0.100 \\
\text { tissue }^{-1} \cdot \mathrm{min}^{-1}\end{array}$ & $3.4 \pm 0.7$ & $3.3 \pm 0.6$ & 0.024 \\
\hline $\begin{array}{l}\text { FBF maximal response to } \\
\text { acetylcholine, } \% \text { of increase }\end{array}$ & $303 \pm 180$ & $318 \pm 183$ & 0.218 \\
\hline $\begin{array}{c}\text { Response to sodium } \\
\text { nitroprusside, \% of increase }\end{array}$ & $317 \pm 110$ & $315 \pm 107$ & 0.784 \\
\hline Vascular resistance, $\mathrm{U}$ & $34+8$ & $34+7$ & 0.998 \\
\hline
\end{tabular}

ALT = alanine transaminase; AST = aspartate transaminase; SBP = systolic blood pressure; $\mathrm{DBP}=$ diastolic blood pressure; $\mathrm{FBF}=$ forearm blood flow; $\gamma$-GT = gamma glutamyltransferase; LDL= low-density lipoproteins; $\mathrm{HDL}=$ high-density lipoproteins; hs-CRP = high-sensitivity C-reactive protein.

\subsection{Vascular Function Evaluation}

Vascular function evaluation was made at 09:00 a.m. in a quiet and air-conditioned room $\left(22-24{ }^{\circ} \mathrm{C}\right)$ with the fasting subjects lying supine. Forearm volume was determined by water displacement. A 20-gauge polyethylene catheter (Vasculon 2; Baxter Healthcare, Deerfield, IL, USA), introduced into the brachial artery of the non-dominant arm, was used for evaluation of blood pressure (BP) and for drug administration. Measurement of percent change in forearm volume was obtained by a mercury-filled silastic strain gauge placed on the widest part of the forearm, connected to a plethysmograph (model EC-4; DE Hokanson, Issaquah, WA, USA) that was connected to a chart recorder for detection of forearm blood flow (FBF) measurements. Exclusion of peripheral venous outflow was obtained by inflating to $40 \mathrm{mmHg}$ a cuff placed on the upper arm with a rapid cuff inflator (model E-10; DE Hokanson, Issaquah, WA, USA). FBF was calculated as the slope of the change in forearm volume; the mean of 3 measurements was obtained at each time point. 
For the evaluation of endothelial function, we used the protocol initially described by Panza et al. [12] and subsequently used by us $[13,14,17,18]$. Endothelium-dependent and endothelium-independent vasodilation was assessed by a dose-response curve during intra-arterial infusions of acetylcholine (ACh) $(7.5,15$, and $30 \mu \mathrm{g} / \mathrm{mL}$ per minute, each for $5 \mathrm{~min})$ and sodium nitroprusside (SNP) $(0.8,1.6$, and $3.2 \mu \mathrm{g} / \mathrm{mL}$ per minute, each for $5 \mathrm{~min}$ ), respectively. Prior to the administration, ACh (Sigma, Milan, Italy) was diluted with saline and SNP (Malesci, Florence, Italy) in 5\% glucose solution, and protected from light with aluminum foil.

\subsection{Statistical Analysis}

Data are reported as mean \pm SD or as percent frequency; we used $t$-test or the $\chi^{2}$ test, as appropriate, for comparisons between groups. Relationships between paired parameters were tested by correlation coefficient of Pearson. Multivariate models (linear or logistic regression) were constructed using, as independent covariates, several traditional CV risk factors-age, gender, body mass index, glucose, LDL and HDL cholesterol, triglyceride, BP, smoking, and e-GFR - to test the independent relationship between $\gamma$-GT and the response to ACh. In an additional analysis, we tested the potential confounding effect of hs-CRP in a subgroup of 400 patients.

In the logistic regression analysis, endothelial dysfunction, as dichotomic variable, was expressed as a maximal response to $\mathrm{ACh}<400 \%$ as previously reported $[17,18]$.

In multiple linear regression models, data were expressed as standardized regression coefficient (beta) and $p$ value. In multiple logistic regression analyses, data were expressed as odds ratio (OR), $95 \%$ confidence interval (CI), and $p$ value.

Receiver operating characteristic (ROC) analysis was used to assess the predictive value of $\gamma$-GT (area under the curve) and to identify the optimal cut-off value of the same variable for endothelial dysfunction, i.e., the value which maximizes the difference between true positive and false positive rates of endothelial dysfunction.

To assess the internal consistency of study results, a sensitivity analysis was performed by randomly dividing the whole study population into two equally sized subgroups.

All calculations were made with a standard statistical package (SPSS for Windows version 20.0; SPSS, Inc., Chicago, IL, USA).

\section{Results}

Baseline demographic, clinical, and hemodynamic characteristics of the whole study population and of the subgroup of 400 patients, with hs-CRP dosage, are summarized in Table 1.

\subsection{Correlational Analysis}

The results of univariate linear analysis between ACh-stimulated vasodilation and different covariates in the study population are reported in Table 2. An inverse relationship was found between peak percent increase in ACh-stimulated vasodilation and the following: $\gamma$-GT $(-0.587)$, accounting for $34.4 \%$ of its variation; ALT $(r=-0.559)$, accounting for $31.2 \%$ of its variation; AST $(r=-0.464)$, accounting for $21.5 \%$ of its variation; age $(r=-0.171)$, accounting for $2.9 \%$ of its variation; BMI $(r=-0.152)$, accounting for $2.3 \%$ of its variation; and fasting glucose $(r=-101)$, accounting for $1 \%$ of its variation. On the contrary, a direct relationship was observed with the following covariates: e-GFR $(r=0.257)$, accounting for $6.6 \%$ of its variation and HDL cholesterol $(r=0.108)$, accounting for $1.2 \%$ of its variation. No significant relationships were detected between ACh-stimulated FBF and systolic and diastolic BP, triglyceride, and LDL cholesterol. 
Table 2. Univariate relationships between FBF maximal response to acetylcholine and different covariates.

\begin{tabular}{ccc}
\hline & $\boldsymbol{R}$ & $\boldsymbol{p}$ \\
\hline$\gamma$-GT, UI/L & -0.587 & 0.0001 \\
\hline ALT, UI/L & -0.559 & 0.0001 \\
\hline AST, UI/L & -0.464 & 0.0001 \\
\hline e-GFR, $\mathrm{mL} / \mathrm{min} / 1.73 / \mathrm{m}^{2}$ & 0257 & 0.0001 \\
\hline Gender, male vs. female & 0.191 & 0.0001 \\
\hline Age, years & -0.171 & 0.0001 \\
\hline BMI, kg/m ${ }^{2}$ & -0.152 & 0.0001 \\
\hline Fasting glucose, $\mathrm{mg} / \mathrm{dL}$ & -0.101 & 0.012 \\
\hline Systolic blood pressure, $\mathrm{mmHg}$ & -0.055 & 0.0108 \\
\hline Diastolic blood pressure, $\mathrm{mmHg}$ & -0.031 & 0.248 \\
\hline Smoking, yes vs. no & 0.028 & 0.269 \\
\hline LDL cholesterol, $\mathrm{mg} / \mathrm{dL}$ & -0.024 & 0.300 \\
\hline Triglycerides, $\mathrm{mg} / \mathrm{dL}$ & -0.007 & 0.435 \\
\hline HDL cholesterol, $\mathrm{mg} / \mathrm{dL}$ & 0.001 & 0.494 \\
\hline
\end{tabular}

Data are expressed as Pearson product-moment correlation coefficient $(r)$ and $p$ values. ALT $=$ alanine transaminase; $\mathrm{AST}=$ aspartate transaminase $; \mathrm{BMI}=$ body mass index; $\gamma$-GT = gamma glutamyltransferase $; \mathrm{HDL}=$ high-density lipoproteins; LDL = low-density lipoproteins.

\subsection{Multivariate Analysis}

To evaluate the independent predictors of ACh-stimulated maximal FBF, covariates reaching statistical significance, with the addition of smoking and gender as dichotomic variables, were inserted into a stepwise multivariate regression model (Table 3). Results of this analysis demonstrated that the variables significantly associated with endothelium-dependent vasodilation were $\gamma$-GT $(\beta=-0.362$; $p=0.0001)$, ALT $(\beta=-0.297 ; p=0.0001)$, AST $(\beta=-0.217 ; p=0.0001)$, e-GFR $(\beta=0.199 ; p=0.0001)$, gender $(\beta=0.166 ; p=0.0001)$, and smoking $(\beta=-0.061 ; p=0.044)$. $\gamma$-GT and ALT account for $35.4 \%$ and $12.3 \%$ of the FBF variation, respectively, while other covariates retained in the final model explain another $9.8 \%$ of its variation. Overall, the final model accounts for $56.5 \%$ of FBF variation.

Table 3. Multiple linear regression models for FBF maximal response to acetylcholine.

\begin{tabular}{ccccc}
\hline & Partial $\mathbf{r}^{2}$ & Total $\mathbf{r}^{2}$ & b Coefficient & $\boldsymbol{P}$ \\
\hline$\gamma$-GT & 35.4 & 35.4 & -0.362 & 0.0001 \\
\hline ALT & 12.3 & 46.7 & -0.297 & 0.0001 \\
\hline AST & 5.4 & 52.1 & -0.217 & 0.0001 \\
\hline e-GFR & 1.9 & 54.0 & 0.199 & 0.0001 \\
\hline Gender & 2.1 & 56.1 & 0.166 & 0.0001 \\
\hline Smoking & 0.4 & 56.5 & -0.061 & 0.044 \\
\hline
\end{tabular}

In the additional analysis including serum hs-CRP, conducted in a subgroup of 400 patients, the association between serum $\gamma$-GT and the peak percent of increase of ACh-stimulated FBF did not change $(\beta=-0.362 ; p=0.0001)$.

Finally, we performed multiple logistic regression analyses to estimate the odds of endothelial dysfunction, adopting the cut-off value of $400 \%$ of increase in FBF as the dependent variable, associated with serum $\gamma$-GT levels (Table 4). The probability of endothelial dysfunction was significantly 
increased by $\gamma$-GT $(\mathrm{OR}=1.927$ for $10 \mathrm{UI} / \mathrm{L}), \mathrm{ALT}(\mathrm{OR}=2.175$ for $10 \mathrm{UI} / \mathrm{L})$, AST (OR = 1.973 for $10 \mathrm{UI} / \mathrm{L})$, and gender ( $\mathrm{OR}=2.695$ male vs. female); on the contrary, the risk of endothelial function impairment was significantly reduced by the preservation of e-GFR (OR $=0.699$ for $\left.10 \mathrm{~mL} / \mathrm{min} / 1.73 \mathrm{~m}^{2}\right)$. The additional analysis, including serum hs-CRP in the same model, demonstrated that the link between serum $\gamma$-GT and endothelial dysfunction did not change (OR $=1.953 ; 95 \% \mathrm{CI}=1.527-2.499 ; p=0.0001$ ).

Table 4. Multiple logistic analysis of endothelial dysfunction.

\begin{tabular}{cccc}
\hline & OR & $\mathbf{9 5 \% ~ C I ~}$ & $p$ \\
\hline$\gamma$-GT, 10 UI/L & 1.927 & $1.548-2.399$ & 0.0001 \\
\hline ALT, 10 UI/L & 2.175 & $1.608-2.941$ & 0.0001 \\
\hline AST, 10 UI/L & 1.973 & $1.369-2.788$ & 0.0001 \\
\hline Gender, male vs. female & 2.695 & $1.413-5.141$ & 0.003 \\
\hline e-GFR, $10 \mathrm{~mL} / \mathrm{min} / 1.73 / \mathrm{m}^{2}$ & 0.699 & $0.583-0.837$ & 0.0001 \\
\hline
\end{tabular}

$\mathrm{ALT}=$ alanine transaminase; $\mathrm{AST}=$ aspartate transaminase; $\gamma$-GT = gamma glutamyltransferase.

The ROC analysis demonstrated that the accuracy of $\gamma$-GT for identifying patients with endothelial dysfunction was 82.1\% (AUC $=0.821, p<0.001$ ) (Figure 1 ) and that the optimal $\gamma$-GT cut-off value for discriminating patients with this alteration from those without was $27 \mathrm{UI} / \mathrm{L}$, a threshold providing a $81 \%$ sensitivity and a $74 \%$ specificity.

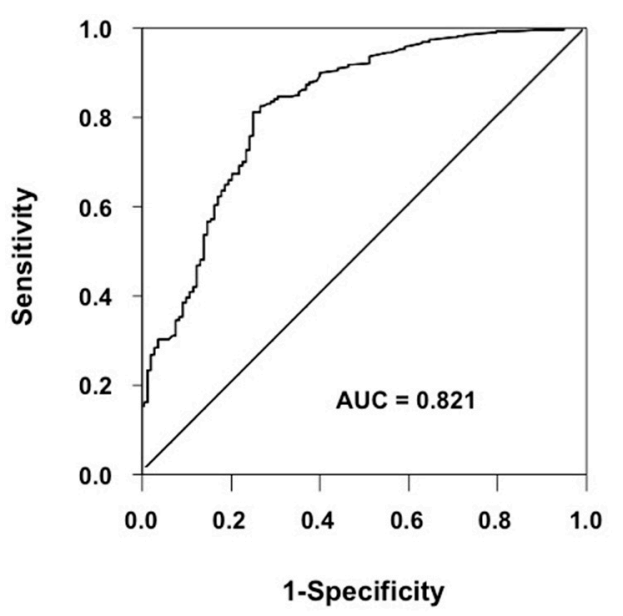

Figure 1. Receiver operating characteristic (ROC) curve for the accuracy of $\gamma$-GT for identifying patients with endothelial dysfunction. The accuracy of $\gamma$-GT for identifying patients with endothelial dysfunction is $82.1 \%$ (AUC $=0.821, p<0.001)$.

\subsection{Cross-Validation}

To assess the robustness of study results, we performed a sensitivity analysis by randomly dividing the whole study population into two equally sized subgroups. This additional analysis showed that the strength of the relationships between the key risk factors (namely, $\gamma$-GT, ALT, AST, gender, and e-GFR) with the outcome variable (endothelial dysfunction) we found in the whole study population (see Table 4) was of similar magnitude to that found in subgroup A (see Table 5) and subgroup B (see Table 6) of the sensitivity analysis. The AUC in the two subgroups (Subgroup A: 76.9\%; Subgroup B: $82.1 \%$ ) provided by the above-mentioned risk factors was almost identical to that found in the whole study population $(82.1 \%)$, indicating an adequate internal consistency of study results. 
Table 5. Multiple logistic analysis of endothelial dysfunction in Subgroup A ( $n=247)$.

\begin{tabular}{cccc}
\hline & OR & $\mathbf{9 5 \% ~ C I ~}$ & $p$ \\
\hline$\gamma$-GT, 10 UI/L & 2.089 & $1.545-2.823$ & 0.0001 \\
\hline ALT, 10 UI/L & 1.556 & $1.045-2.316$ & 0.029 \\
\hline AST, 10 UI/L & 1.865 & $1.146-3.035$ & 0.019 \\
\hline Gender, male vs. female & 2.742 & $1.147-6.558$ & 0.023 \\
\hline e-GFR, 10 $\mathrm{mL} / \mathrm{min} / 1.73 / \mathrm{m}^{2}$ & 0.656 & $0.522-0.825$ & 0.0001 \\
\hline
\end{tabular}

Table 6. Multiple logistic analysis of endothelial dysfunction in Subgroup B $(n=253)$.

\begin{tabular}{cccc}
\hline & OR & $\mathbf{9 5 \% ~ C I ~}$ & $p$ \\
\hline$\gamma$-GT, 10 UI/L & 1.819 & $1.335-2.480$ & 0.0001 \\
\hline ALT, 10 UI/L & 2.733 & $1.747-4.273$ & 0.0001 \\
\hline AST, 10 UI/L & 1.831 & $1.141-2.937$ & 0.012 \\
\hline Gender, male vs. female & 2.014 & $0.827-4.904$ & 0.123 \\
\hline e-GFR, $10 \mathrm{~mL} / \mathrm{min} / 1.73 / \mathrm{m}^{2}$ & 0.710 & $0.558-0.903$ & 0.005 \\
\hline
\end{tabular}

\section{Discussion}

To our knowledge, findings obtained in this study demonstrate, for the first time, the association between serum $\gamma$-GT within the normal range and endothelial dysfunction, evaluated by strain-gauge plethysmography, in a very large and well-characterized population of never-treated hypertensive patients. Particularly, the risk of endothelial dysfunction increases by $93 \%$ for each $10 \mathrm{IU} / \mathrm{L}$ elevation of this enzyme (Table 4).

It is well established that the primary role of $\gamma$-GT is to contribute to the maintenance of intracellular homeostasis of glutathione (GSH), one of the major intracellular antioxidant components [20], even if some experimental findings demonstrated that, in the presence of iron or other transition metals, it might also be involved in the generation of ROS [9]. Thus, on the basis of this evidence, $\gamma$-GT emerged over time as an early and sensitive enzyme related to oxidative stress. In fact, its circulating levels, within normal range, resulted in the increase of F2-isoprostanes, fibrinogen, and CRP, all markers of systemic inflammation [9]. Interestingly, this association was observed independently of the presence of metabolic alterations, typically related to $\gamma$-GT elevation $[5,21]$. Consistent with these findings, we also observed a significant relationship between $\gamma$-GT and hs-CRP, confirming previously published data suggesting that elevation of $\gamma$-GT is involved in the subclinical inflammatory response and oxidative stress [22], both conditions associated with endothelial dysfunction [13,23].

Another important finding of this study is that ALT levels, within the normal range, are also significantly associated with endothelial function. Particularly, the increase of $10 \mathrm{IU} / \mathrm{L}$ of ALT almost doubles the risk of endothelial dysfunction, as reported in Table 4. Although a significant relationship between $\gamma$-GT values within the normal range and the incidence of chronic elevation of ALT was previously reported [24], no data are available to demonstrate a possible pathogenetic role of ALT in the activation of an oxidative stress process. Although $\gamma$-GT can be considered as an early biomarker of systemic and hepatic oxidative stress, ALT elevation might reflect possible inflammatory liver damage as a consequence of this increased oxidative stress. In accordance with this, we previously reported that hypertensive patients with both metabolic syndrome and non-alcoholic fatty liver disease (NAFLD) had a reduced endothelium-dependent vasodilation in comparison with hypertensives with metabolic syndrome without NAFLD [25]. Serum ALT values were significantly higher in hypertensives with NAFLD than in those without $(42.0+10.8$ vs. $24.6+5.2 \mathrm{UI} / \mathrm{L})$, leading to the hypothesis that NAFLD-and the associated elevation of ALT levels-could be considered as an early biomarker of endothelial dysfunction. 


\section{Conclusions}

The results obtained in the present study showed a strong and inverse relationship between $\gamma$-GT and endothelium-dependent vasodilation; in particular, the novelty of this paper is the identification of a cut-off value of $\gamma$-GT (27 IU/L) to discriminate between patients with and without ( $\gamma$-GT $>$ and $<27 \mathrm{IU} / \mathrm{L}$, respectively) endothelial dysfunction. In addition, present data confirm previously published literature demonstrating the strong associations between serum $\gamma$-GT and many CV risk factors and/or events; in this context endothelial dysfunction could be considered as an established consequence of increased oxidative stress. Furthermore, it is important to remark that strain-gauge plethysmography represents the gold-standard technique for endothelial function testing, thus conferring robustness to the results obtained in a wide population. Thus, serum $\gamma$-GT may be considered an additional biomarker of early vascular damage; its usefulness is also supported by its wide availability and low cost.

Author Contributions: Conceptualization, R.M., M.P., F.P.; methodology, M.P., F.P.; formal analysis and investigation, A.S., E.S., F.M., B.C., S.G., F.M. and F.A.; writing-original draft preparation, R.M., M.P.; writing-review and editing: M.P., F.P.; supervision, F.P. and G.S. All authors have read and agreed to the published version of the manuscript.

Funding: This research received no external funding.

Conflicts of Interest: The authors declare no conflict of interest.

\section{References}

1. Kunutsor, S.K. Gamma-glutamyltransferase-friend or foe within? Liv. Int. 2016, 36, 1723-1734. [CrossRef] [PubMed]

2. Lee, D.; Silventoinen, K.; Jacobs, D.R.; Jousilahti, P.; Tuomileto, J. Glutamyltransferase, Obesity, and the Risk of Type 2 Diabetes: Observational Cohort Study among 20,158 Middle-Aged Men and Women. J. Clin. Endocrinol. Metab. 2004, 89, 5410-5414. [CrossRef] [PubMed]

3. Ko, S.H.; Baeg, M.K.; Han, K.D.; Ko, S.Y.; Shin, S.B.; Ko, S.H.; Ahn, Y.B. Association between gamma-glutamyltransferase and albuminuria in non diabetic adults with normal renal function. Clin. Exp. Nephrol. 2017, 21, 835-841. [CrossRef] [PubMed]

4. Mason, J.E.; Starke, R.D.; Van Kirk, J.E. Gamma-Glutamyl Transferase: A Novel Cardiovascular Risk BioMarker. Prev. Cardiol. 2010, 13, 36-41. [CrossRef]

5. Turgut, O.; Tandogan, I.; Tandoğan, I. Gamma-glutamyltransferase to Determine Cardiovascular Risk: Shifting the Paradigm Forward. J. Atheroscler. Thromb. 2011, 18, 177-181. [CrossRef]

6. Aksakal, E.; Tanboga, I.H.; Kurt, M.; Kaygın, M.A.; Kaya, A.; Isik, T.; Ekinci, M.; Sevimli, S.; Acikel, M. The relation of serum gamma-glutamyl transferase levels with coronary lesion complexity and long-term outcome in patients with stable coronary artery disease. Atherosclerosis 2012, 221, 596-601. [CrossRef]

7. Li, D.D.; Xu, T.; Cheng, X.Q.; Wu, W.; Ye, Y.C.; Guo, X.Z.; Cheng, Q.; Liu, Q.; Liu, L.; Zhu, G.J.; et al. Serum Gamma-Glutamyltransferase Levels are Associated with Cardiovascular Risk Factors in China: A Nationwide Population-Based Study. Sci. Rep. 2018, 8, 16533. [CrossRef]

8. Paolicchi, A.; Minotti, G.; Tonarelli, P.; Tongiani, R.; De Cesare, D.; Mezzetti, A.; Dominici, S.; Comporti, M.; Pompella, A. Gamma-glutamyl transpeptidase-dependent iron reduction and LDL oxidation-A potential mechanism in atherosclerosis. J. Investig. Med. 1999, 47, 151-160.

9. Lee, D.; Blomhoff, R.; Jacobs, D.R. ReviewIs Serum Gamma Glutamyltransferase a Marker of Oxidative Stress? Free. Radic. Res. 2004, 38, 535-539. [CrossRef]

10. Ross, R. Atherosclerosis-An inflammatory disease. N. Engl. J. Med. 1999, 340, 115-126. [CrossRef]

11. Vane, J.R.; Anggard, E.E.; Botting, R.M. Regulatory functions on the vascular endothelium. N. Engl. J. Med. 1990, 323, 27-36.

12. Panza, J.A.; Quyyumi, A.A.; Brush, J.E.; Epstein, S.E. Abnormal Endothelium-Dependent Vascular Relaxation in Patients with Essential Hypertension. New. Engl. J. Med. 1990, 323, 22-27. [CrossRef] [PubMed]

13. Perticone, F.; Ceravolo, R.; Candigliota, M.; Ventura, G.; Iacopino, S.; Sinopoli, F.; Mattioli, P.L. Obesity and body fat distribution induce endothelial dysfunction by oxidative stress: Protective effect of vitamin C. Diabetes 2001, 50, 159-165. [CrossRef] [PubMed] 
14. Perticone, F.; Ceravolo, R.; Pujia, A.; Ventura, G.; Iacopino, S.; Scozzafava, A.; Ferraro, A.; Chello, M.; Mastroroberto, P.; Verdecchia, P.; et al. Prognostic significance of endothelial dysfunction in hypertensive patients. Circulation 2001, 104, 191-196. [CrossRef] [PubMed]

15. Quyyumi, A.A. Endothelial function in health and disease: New insights into the genesis of cardiovascular disease. Am. J. Med. 1998, 105, 32S-39S. [CrossRef]

16. Bonetti, O.; Lerman, P.; Lerman, L.O. Endothelial dysfunction: A marker of atherosclerotic risk. Arter. Thromb. Vasc. Boil. 2003, 23, 168-175. [CrossRef]

17. Perticone, F.; Maio, R.; Perticone, M.; Sciacqua, A.; Shehaj, E.; Naccarato, P.; Sesti, G. Endothelial Dysfunction and Subsequent Decline in Glomerular Filtration Rate in Hypertensive Patients. Circulation 2010, 122, 379-384. [CrossRef]

18. Perticone, F.; Maio, R.; Perticone, M.; Miceli, S.; Sciacqua, A.; Tassone, E.J.; Shehaj, E.; Tripepi, G.; Sesti, G. Endothelial dysfunction predicts regression of hypertensive cardiac mass. Int. J. Cardiol. 2013, 167, 1188-1192. [CrossRef]

19. Halcox, J.; Donald, A.E.; Ellins, E.; Witte, D.; Shipley, M.; Brunner, E.J.; Marmot, M.; Deanfield, J. Endothelial Function Predicts Progression of Carotid Intima-Media Thickness. Circulation 2009, 119, 1005-1012. [CrossRef]

20. Franco, R.; Schoneveld, O.J.; Pappa, A.; Panayiotidis, M.I. The central role of glutathione in the pathophysiology of human diseases. Arch. Physiol. Biochem. 2007, 113, 234-258. [CrossRef]

21. Yamada, J.; Tomiyama, H.; Yambe, M.; Koji, Y.; Motobe, K.; Shiina, K.; Yamamoto, Y.; Yamashina, A. Elevated serum levels of alanine aminotransferase and gamma glutamyltransferase are markers of inflammation and oxidative stress independent of the metabolic syndrome. Atherosclerosis 2006, 189, 198-205. [CrossRef]

22. Lee, D.-H.; Jacobs, D.R. Association between serum gamma-glutamyltransferase and C-reactive protein. Atherosclerosis 2005, 178, 327-330. [CrossRef] [PubMed]

23. Andreozzi, F.; Laratta, E.; Procopio, C.; Hribal, M.L.; Sciacqua, A.; Perticone, M.; Miele, C.; Perticone, F.; Sesti, G. Interleukin-6 Impairs the Insulin Signaling Pathway, Promoting Production of Nitric Oxide in Human Umbilical Vein Endothelial Cells. Mol. Cell. Boil. 2007, 27, 2372-2383. [CrossRef] [PubMed]

24. Lee, D.; Lim, J.-S.; Yang, J.-H.; Ha, M.-H.; Jacobs, D.R. Serum gamma-glutamyltransferase within its normal range predicts a chronic elevation of alanine aminotransferase: A four year follow-up study. Free Radic. Res. 2005, 39, 589-593. [CrossRef] [PubMed]

25. Sciacqua, A.; Perticone, M.; Miceli, S.; Laino, I.; Tassone, E.; Grembiale, R.D.; Andreozzi, F.; Sesti, G.; Perticone, F. Endothelial dysfunction and non-alcoholic liver steatosis in hypertensive patients. Nutr. Metab. Cardiovasc. Dis. 2011, 21, 485-491. [CrossRef] [PubMed] 